Vol. 6 No.2 Tahun 2021

Jurnal Nusantara

Aplikasi Manajemen Bisnis

E-ISSN : 2528-0929 P-ISSN : 2549-5291

\title{
Peran Entrepreneurial Marketing dalam Memediasi Kompetensi Sumber Daya Manusia dan Inovasi untuk mencapai Keunggulan Kompetitif
}

Subagyo ${ }^{1}$, Gesty Ernestivita ${ }^{3}$ Eupharasia Susy Suhendra ${ }^{3}$

Universitas Nusantara PGRI Kediri ${ }^{1,2}$,Universitas Gunadarma Jakarta ${ }^{3}$

subagyo@unpkediri.ac.id ${ }^{1}$, gesty@unpkediri.ac.id ${ }^{2}$, susysuhendra@gmail.com ${ }^{3}$

https://doi.org/10.29407/nusamba.v6i2.16246

\section{Informasi Artikel}

Tanggal masuk 21 Juli 2021

Tanggal revisi 10 September 2021

Tanggal diterima 27 September 2021

\begin{abstract}
The purpose of this study was to determine the effect of HR competence and innovation on competitive advantage with entrepreneurial marketing as a moderating variable in the Food and Beverage Industry in East Java. This research is a survey type with a quantitative approach. The sample was determined as many as 100 food and beverage entrepreneurs in East Java. Sampling with non-probability sampling technique with purposive sampling method. The data collected from the questionnaire was then analyzed using SEM with the Smart PLS application tool. The results of the study conclude that HR competence and entrepreneurial marketing partially have a significant positive effect on competitive advantage, while innovation has no significant effect. $H R$ competence and innovation significantly affect entrepreneurial marketing. Likewise, it is proven that entrepreneurial marketing is proven to be able to mediate HR competencies and innovation to competitive advantage.
\end{abstract}

Keywords: Human Resourre Competence, Innovation, Entrepreneurial Marketng, Competitive Advantage

\begin{abstract}
Abstrak
Tujuan penelitian ini untuk mengetahui pengaruh kompetensi SDM dan inovasi terhadap keunggulan kompetitif dengan entrepreneurial marketing sebagai variabel moderator pada Industri Makanan dan minuman di Jawa Timur. Penelitian ini termasuk jenis survey dengan pendekatan kuantitatif. Sampel ditentukan sebanyak 100 pengusaha makanan dan minuman di Jawa Timur. Pengambilan sampel dengan teknik non probability sampling dengan metode purposive sampling. Data yang dikumpulkan dari angket selanjutnya dianalisis menggunakan SEM dengan alat bantu aplikasi Smart PLS. Hasil penelitian menyimpulkan bahwa kompetensi SDM dan entrepreneurial marketing secara parsial berpengaruh positif signifikan terhadap keunggulan kompetitif, sedangkan inovasi tidak berpengaruh signifikan. Kompetensi SDM dan inovasi secara signifikan berpengaruh terhadap entrepreneurial marketing. Demikian pula terbukti bahwa entrepreneurial marketing terbukti mampu memediasi kompetensi SDM dan inovasi terhadap keunggulan kompetitif.
\end{abstract}

Kata Kunci: Kompetensi SDM, Inovasi, Entrepreneurial Marketing, Keunggulan Kompetitif 


\section{Jurnal Nusantara Aplikasi Manajemen Bisnis}

\section{Jurnal Nusantara}

Vol. 6 No.2 Tahun 2021

Aplikasi Manajemen Bisnis

E-ISSN : 2528-0929 P-ISSN : 2549-5291

\section{Pendahuluan}

Dunia usaha mengalami persaingan yang semakin pesat yang tidak dapat terelakkan akibat tumbuh kembangnya industri [1] . Kondisi ini di satu sisi mampu menciptakan banyak peluang besar, namun di sisi lain akan menciptakan persaingan bisnis yang semakin kompetitif [2], sehingga menuntut setiap perusahaan memiliki keunggulan kompetitif yang menjadi ciri tersendiri agar dapat bertahan dan berkembang dalam kondisi pasar. Keunggulan kompetitif merupakan salah satu modal utama perusahaan dalam mempertahankan eksistensinya di tengah kondisi pasar yang kompetitif [3]. Keunggulan kompetitif merupakan kecakapan yang dimiliki perusahaan dengan kinerja sumberdayanya yang lebih tinggi dan kompeten dibandingkan perusahaan lain dalam sektor industri yang sama [4].

Terdapat beberapa faktor yang mempengaruhi keunggulan kompetitif pada sebuah usaha, di antaranya adalah orientasi pasar, inovasi produk, adaptabilitas lingkungan, orientasi kewirausahaan, pelatihan dan orientasi pasar, dan kemampuan manajemen [5]; [6]. Salah satu sektor usaha yang saat ini memperoleh perhatian besar pemerintah adalah Usaha Mikro Kecil dan Menengah (UMKM), karena UMKM adalah sektor ekonomi yang memiliki posisi krusial bagi Indonesia. UMKM penyumbang terbesar pada sektor ekonomi, dan industri makanan minuman menyumbang sampai $36,40 \%$ pada PDB industri pengolahan nonmigas [7].

Menghadapi persaingan pasar yang kian meningkat para wirausahawan dituntut agar bekerja keras melahirkan inovasi baru untuk mempertahankan dan meningkatkan kualitas produk yang ditawarkan. Selain produk, peningkatan pelayanan juga patut dipertimbangkan. Adanya e-commerce yang melayani segala macam produk makanan minuman berikut pemesanan dan pelayanannya yang mudah harus dapat disikapi dengan baik. Merespon permasalahan ini, maka diperlukan metode dan strategi pemasaran yang tepat, salah satunya melalui entrepreneurial marketing. Menurut [8] ; [9]; [10].

Menurut [11] entrepreneurial marketing adalah identifikasi proaktif dan eksploitasi peluang guna memperoleh sekaligus mempertahankan konsumen yang telah berlangganan dan menguntungkan dengan pendekatan inovatif dalam rangka mengelola risiko, menggunakan SDM dan penciptaan nilai perusahaan. [12] berpendapat bahwa target pasar modern memandang bahwa model keputusan pembelian oleh pelanggan saat ini lebih bersifat emosional yang dalam artian sangat menimbang terkait perasaan, keinginan, dan fantasi daripada berpikir secara rasional. Hal semacam ini menjadikan pendekatan pemasaran menjadi berbeda. Jika dalam pemasaran berbasis tradisional pendekatanya mengacu kepada hal-hal yang bersifat analitik, verbal juga kuantitatif, sebaliknya pendekatan pemasaran modern lebih mengacu kepada visual intuitif walaupun tetap memperhatikan hal-hal yang verbal. Maka, tak jarang banyak warga negara Indonesia yang memilih mengkonsumsi makanan, karena kemasannya yang menarik, tempatnya yang hits dan instagramable dibandingkan dengan rasa yang dimiliki [13]. Dalam Era yang semakin kompleks, UMKM harus bisa menerapkan entrepreneurial marketing demi meningkatkan efisisensi tujuan perusahaan.

Penting bagi perusahaan mengetahui strategi yang tepat untuk memasarkan produk yang dijual, karena strategi pemasaran yang tepat akan membuat produk mudah diterima oleh calon pembeli.Keberhasilan pemasaran produk juga tergantung pada kiat dan strategi pemasaran yang diterapkan, karena mampu menciptakan dan mempertahankan permintaan 


\section{Jurnal Nusantara Aplikasi Manajemen Bisnis}

\section{Jurnal Nusantara}

Aplikasi Manajemen Bisnis

Vol. 6 No.2 Tahun 2021

pelanggan yang kredibel dan berkelanjutan.Apabila omzet penjualan berangsur-angsur mulai melambat, maka perlu dilakukan analisis apakah terkait dengan strategi pemasaran yang tidak efektif yang diterapkan, atau karena adanya perubahan preferensi dan perilaku konsumen.

Dalam rangka mencapaikeunggulan kompetitif, maka dibutuhkan adanya kompetensi SDM yang sesuai dan handal dalam melaksanakan tugasnya. Menurut [14]; [15]; [14] SDM merupakan bagian penting dari aset inti perusahaan. Dalam sistem perusahaan, keberhasilan atau kegagalan tujuan perusahaan ditentukan, dan perusahaan perlu lebih memperhatikan. Untuk itu, tidak cukup bagi perusahaan untuk menemukan karyawan yang tepat untuk posisi tersebut, tetapi setiap orang harus memiliki keterampilan yang diperlukan.

Sumber daya manusia juga memiliki keterkaitan dengan proses entrepreneurial marketing. Menurut [14] kompetensi SDM dapat berpengaruh positif terhadap entrepreneurial marketing. Salah satu kunci keberhasilan program perusahaan adalah peranan sumber saya manusia. Sumber daya manusia yang kreatif dengan dengan kapabilitas yang baik, memiliki analisis yang kuat dalam memprediksi kondisi pasar mempengaruhi eksistensi perusahaan. Dengan kemampuan tersebut, perusahaan dapat lebih cepat menciptakan produk produk sesuai dengan kebutuhan dan keinginan konsumen.

Selain kompetensi SDM, inovasi juga memegang peranan penting terhadap keunggulan kompetitif. Inovasi merupakan keharusan bagi pelaku usaha, dan inovasi sangat relevan dengan karakteristik enterpreneurial marketing yang sangat peka terhadap perubahan. Menurut [17]; [18]; [11] inovasi yang dilakukan perusahaan dapat berpengaruh terhadap entrepreneurial marketing. Untuk menghadapi persaingan bisnis yang kompetitif, perusahaan perlu melakukan gebrakan dengan meningkatkan kinerja pemasaran agar dapat memperluas pangsa pasar, peningkatan omset penjualan dan peningkatan laba.

Di era milenium ini, pasar tampak semakin penting dalam memenangkan persaingan. Keinginan dan kebutuhan yang berubah dengan cepat mendesak perusahaan untuk dapat adaptif dengan melakukan berbagai inovasi yang relevan dengan perkembangan zaman. Salah satu alasannya adalah karena pelanggan juga memiliki masa atau tidak selamanya mengkonsumsi produk yang sama, sehingga pada fakta di lapangan memungkinkan konsumen akan memilih membeli produk yang berasal dari perusahaan lain yang dirasa mampu memenuhi kebutuha mereka. Oleh karena itu, inovasi berkelanjutan diperlukan perusahaan agar dapat bertahan dengan usahanya. Inovasi yang dilakukan perusahaan mampu mempengaruhi segala aspek perusahaan termasuk bagaimana produk dipasarkan.

Inovasi mampu merubah cara kerja produksi, tampilan produk sampai produk dipasarkan. Dalam membeli produk, konsumen tidak hanya melihat pada nilai akhir atau manfaat dari suatu produk yang diperlukan, tetapi konsumen juga mempertimbangkan apakah produk yang dipilih mempunyai value dibanding dengan produk lain sejenis. Menurut [19]; [20]; [21]; [22]; [23]; [24] inovasi yang dilakukan perusahaan mampu mempengaruhi keunggulan kompetitif perusahaan. Dengan memberikan inovasi yang kreatif diharapkan perusahaan mampu menciptakan produk dengan karakteristik yang berbeda dan memiliki keunggulan lebih dari produk yang pernah ada dari perusahaan lain.

Kompetensi SDM dan kemampuan inovasi adalah faktor yang sangat penting untuk mencapai keunggulan kompetitif perusahaan. [25] mengemukakan bahwa enterpreneurial marketing merupakan salah satu taktik yang cocok diterapkan dalam usaha indrustri kecil 


\section{Jurnal Nusantara Aplikasi Manajemen Bisnis}

\section{Jurnal Nusantara}

Aplikasi Manajemen Bisnis

Vol. 6 No.2 Tahun 2021

dan menengah, dikarenakan mayoritas usaha kecil menengah mempunyai keterbatasan sumber daya, sehingga harus menggunakan taktik kreatif. Degan entrepeneur marketing diharapkan mampu memediasi kompetensi SDM dan inovasi terhadap keunggulan bersaing.

Mendasarkan uraian di atas, penelitian ini memiliki tujuan untuk mengetahui pengaruh kompetensi SDM dan inovasi terhadap keunggulan bersaing dengan entrepreneurial marketing sebagai variabel mediasi pada Industri Makanan dan Minuman di Jawa Timur.

\section{Keunggulan Kompetitif}

Keunggulan kompetitif diartikan sebagai posisi prestisius yang dimiliki perusahaan dimana perusahaan memiliki posisi pasar yang lebih kuat dalam suatu industri dibandingkan dengan pesaing [26] . Keunggulan kompetitif dapat terwujud ketika perusahaan memiliki sumber daya yang kompeten dan karakteristik tersendiri. Keunggulan kompetitif ditentukan oleh dua hal utama kekuatan, yaitu kekuatan endogen dari sumber daya dan kemampuan dan kekuatan eksogen dari pasar posisi dalam suatu industri. [27] mendefinisikan competitive advantage sebagai pralktik terbaik perusahaan dalam menciptakan sumber daya saing baru. Dalam dunia persaingan pada dasarnya semua perusahaan berlomba-lomba untuk lebih unggul dalam papan persaingan. Umumnya setiap perusahaan memiliki strategi untuk bersiang secara eksplisit dengan melaksanakan kegiatan-kegiatan dari banyak departemen fungsional yang dimiliki perusahan. Penciptaan strategi yang sukses sangat penting untuk masa depan perusahaan, karena strategi harus dirancang untuk menghasilkan keunggulan kompetitif yang berkelanjutan untuk memiliki pangsa pasar.

Ketika sebuah perusahaan berusaha mempertahankan laba diatas rata-rata yang diperoleh oleh perusahaan sejenis, maka bisa dikatakan perusahaan tersebut mempunyai keunggulan bersaing yang baik. Banyaknya strategi bisnis bertujuan untuk mencapai keunggulan kompetetif yang permanen [28]. Tujuan dari strategi ini adalah memiliki biaya yang lebih rendah daripada pesaingnya. Jadi, dalam strategi ini yang terpenting adalah efisiensi kerja. Fakta bahwa biaya rendah menawarkan perusahaan peluang yang lebih baik untuk menghasilkan keuntungan dan menjadi sangat tahan jika terlibat dalam perang harga dengan pesaing [29]. Menurut [5] keunggulan kompetitif disebabkan atas orientasi pasar, inovasi produk dan adaptabilitas lingkungan. [6] menemukan bahwa orientasi kewirausahaan, pelatihan, orientasi pasar dan kemampuan manajemen mempengaruhi keunggulan kompetitif. [30] mengemukakan bahwa keunggulan kompetitif terbagi dalam beberapa indikator, yakni harga/biaya, kualitas, keandalan pengiriman, inovasi produk dan ketepatan pasar.

\section{Enterpreneurial Marketing}

Menurut [31] enterpreneurial marketing didefinisikan sebagai taktik pemasaran yang tidak terencana, nonlinier, dan visioner yang diterapkan oleh para pengusaha. Enterpreneurial marketing merupakan kemampuan untuk selalu adaptif terhadap perkembangan zaman, inovatif, berorientasi pada peluang untuk membawa produk pada 


\section{Jurnal Nusantara Aplikasi Manajemen Bisnis}

\section{Jurnal Nusantara}

Vol. 6 No.2 Tahun 2021

Aplikasi Manajemen Bisnis

E-ISSN : 2528-0929 P-ISSN : 2549-5291

pasar dan memenuhi kebutuhan pasar [32]. [33] menyatakan bahwa pemasaran UKM sebenarnya adalah pemasaran kewirausahaan. [34] menekankan bahwa ada empat prinsip entrepreneurrial marketing, yaitu konsep, strategi, metode, dan intelejensi pasar.

[25] mengemukakan bahwa enterpreneurial marketing merupakan salah satu taktik yang cocok diterapkan dalam usaha indrustri kecil dan menengah, karena sebagian besar usaha kecil dan menengah memiliki keterbatasan sumber daya, sehingga harus menggunakan cara yang kreatif. Menurut [35] salah satu taktik yang dapat digunakan dalam menciptakan keunggulan kompetitif di Era 21 yaitu menggunakan startegi entrepreneurial marketing.

Hasil penelitian [9] dan [10] menunjukkan bahwa pemasaran komersial mempengaruhi kinerja pemasaran karena memainkan keunggulan kompetitif sebagai perantara kinerja pemasaran. Demikia pula hasil penelitian [10] dimana entrepreneurial marketing berpengaruh terhadap kinerja perusahaan dan keunggulan kompetitif. [8] mengemukakan bahwa entrepreneurial marketing berpengaruh terhadap hasil yang dicapai UKM.

[36] menemukan bahwa entrepreneurial marketing dan inovasi memiliki hubungan erat yang saling bertautan. Hasil yang sama juga ditemukan oleh [37] dimana inovasi dan proses pemasaran dalam perusahaan memiliki hubungan satu sama lain. Temuan [17] menunjukkan bahwa semua dimensi inovasi (inovasi produk, proses, organisasi dan pemasaran) secara signifikan berpengaruh terhadap kinerja pemasaran perusahaan. Menurut [31] terdapat tujuh indikator untuk pemasaran bisnis, yaitu proactiveness (proaktif), calculated risk-taking (pengambilan keputusan dengan memperhatikan risiko), opportunity focus (fokus pada peluang), resource leveraging (pemanfaatan sumberdaya), customer intensity (intensitas pelanggan ) dan value creation (penciptaan nilai) .

\section{Kompetensi SDM}

SDM memegang fungsi krusial dalam sebuah perusahaan.SDM merupakan penyangga utama sekaligus sebagai roda penggerak suatu perusahaan dalam mencapai atau mewujudkan visi dan misi sebuah perusahaan. Penguatan kompetensi SDM diwujudkan mulai dari proses rekruitment sampai pemberian remun. [38] mengemukakan bahwa kompetensi SDM akan memudahkan terselesaikannya suatu proyek yang selanjutnya akan menciptakan keunggulan kompetitif bagi perusahaan. Kompetensi SDM mempengaruhi semua aktivitas dalam sebuah usaha, termasuk bagaimana strategi pemasaran dilakukan. [39] menegaskan bahwa, dalam kegiatan entrepreneurial marketing yang dilakukan UMKM, sumber daya manusia yang ada harus mampu bersikap fleksibel dengan tidak mengikuti strategi pemasaran yang dilakukan perusahaan besar, hal ini dikarenakan keterbatasan SDM dan keuangan yang dimiliki. UMKM memerlukan adanya SDM yang responsif dalam menanggapi kebutuhan dan peluang pasar, serta konsisten untuk mengenalkan produk pada pasar yang lebih luas.

[14] dalam penelitiannya yang mengambil responden karyawan pada enam puluh tiga perusahaan manufaktur, menyimpulkan bahwa praktik SDM mempunyai pengaruh positif dan signifikan berdampak pada keunggulan kompetitif. Peningkatan kompetensi SDM akan membawa hasil operasional yang lebih baik untuk mencapai kinerja organisasi yang lebih tinggi. Hal ini dapat diartikan bahwa SDM mempunyai peranan penting dalam usaha menciptakan keunggulan kompetitif sebuah perusahaan. Menurut [16] keunggulan 


\section{Jurnal Nusantara Aplikasi Manajemen Bisnis}

\section{Jurnal Nusantara}

Aplikasi Manajemen Bisnis

Vol. 6 No.2 Tahun 2021

kompetitif dipengaruhi oleh kompetensi SDM. Indikator kompetensi SDM menurut [40] yaitu pengetahuan, keterampilan (skill), kosep diri (self concept) dan motif (motive).

\section{Inovasi Perusahaan}

Inovasi sangat penting untuk keberlanjutan perusahaan agar unggul dalam persiangan di lingkungan bisnis. Untuk melakukan inovasi, perusahaan perlu mengadopsi berbagai kegiatan inovasi dalam semua aktivitas perusahaan [41]. Inovasi adalah proses identifikasi peluang yang bertujuan menciptakan produk, layanan, atau praktik kerja baru. Perusahaan yang mampu mengembangkan produk, layanan, dan proses baru dapat berpengaruh terhadap kinerja perusahaan dan merupakan investasi jangka panjang [42] .

[43] telah melakukan penelitin mengenai inovasi perusahaan dengan survey terhadap 194 manajer perusahaan di Australia. Hasil penelitiannya menunjukkan bahwa inovasi melalui pengembangan teknologi dapat lebih efektif dalam mencapai tujuan perusahaan. Hasil serupa juga ditemukan oleh [44] yang melakukan penelitian pada manajer tingkat atas dari 113 perusahaan pemasok otomotif di Turki, pada tahun 2011. Hasil penelitiannya menunjukkan bahwa inovasi teknologi, baik dalam produk maupun proses berpengaruh positif dan signifikan terhadap kinerja perusahaan. Menurut [45] keungguan bersaing disebabkan karena perusahaan mampu melakukan inovasi dalam hal fitur maupun kinerja fungsional yang akan mempengaruhi keuntungan finansial. [46] mengemukakan bahwa inovasi merupakan salah satu bagian utama berjalannya entrepreneurial marketing. Entrepreneurial marketing memiliki tiga bidang utama yakni fokus pada perubahan; oportunistik; dan inovasi.

[20] mengemukakan bahwa manajemen inovasi yang tepat mampu memberikan keunggulan kompetitif. Inovasi memiliki tujuan utama untuk memenuhi permintaan pasar sehingga dengannya inovasi dianggap sebagai strategi yang bisa dipakai dalam mencapai keunggulan kompetitif untuk sebuah perusahaan. [24] dalam penelitiannya yang melibatkan 150 UMKM di Selangor menyimpulkan bahwa keunggulan kompetitif dipengaruhi oleh orientasi pasar dan inovasi. Hasil serupa juga ditemukan oleh [21] dimana kecepatan inovasi dapat berpengaruh terhadap keunggulan kompetitif perusahaan. Menurut [47] ada empat indikator inovasi yaitu: inovasi produk, proses, pemasaran dan organisasi.

Mendasarkan pada kajian teori di atas dapat digambarkan kerangka konsep penelitian berikut:

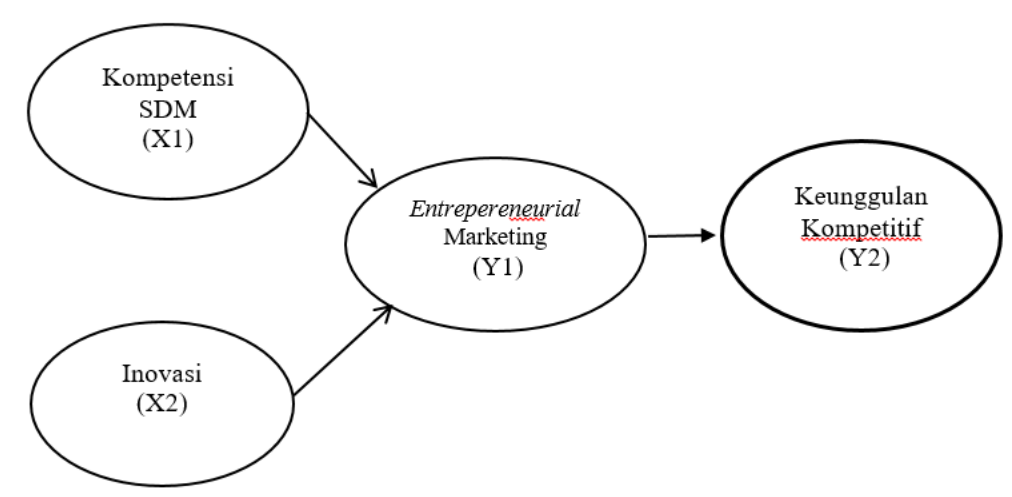

Gambar 1. Kerangka Konsep Penelitian 


\section{Jurnal Nusantara Aplikasi Manajemen Bisnis}

\section{Metode}

Penenelitian ini merupakan jenis penelitian survey dengan pendekatan kuantitatif. Populasinya adalah pelaku industri makanan dan minuman di Jawa Timur yang jumlahnya tidak diketahui dengan pasti. Ukuran sampel didasarkan pada jumlah sampel minimum dan memperhitungkan jumlah variabel yang diuji. Menurut [48] jika jumlah sampel dengan variabel $\leq 5$, maka banyaknya sampel adalah 100 . Teknik pengambilan sampel yang digunakan adalah non probability sampling dengan metode purposive sampling. Kriteria sampel adalah usaha sudah berjalan minimal 2 tahun dan omset penjualan maksimal Rp 2,5 milyar per tahun.

Data dikumpulkan dengan menggunakan angket yang disebar menggunakan googleform yang dikirim kepada pelaku industri makanan minuman yang tergabung WAG berbagai asosiasi UMKM di Jawa Timur. Setelah data terkumpul selanjutnya dianalisis menggunakan Struktural Equation Model (SEM) berbantuan aplikasi Smart PLS. Mendasarkan pada [49], maka tahapan analisis data pada penelitian ini yaitu:

a. Tahap Measurement Model. Tahapan ini merupakan tahap pengujian instrument, yaitu pengujian validitas dan reliabilitas berbagai indikator. Instrumen dinyatakan valid apabila $\mathrm{r}_{\text {hitung }}>\mathrm{r}_{\text {tabel }}$ pada $\alpha=0.05$, dan apabila nilai cronbach's alpha $>0.6$ maka dianggap reliabel.

b. Tahap Uji Structural Model. Tahap ini merupakan tahap pengujian hipotesis yang memiliki tujuan melihat ada atau tidaknya pengaruh antara variabel atau hubungan konstruk yang diukur secara statistik dengan menggunakan Smart PLS. Struktural disebut juga inner model diukur dengan melihat $r$-square yang memperliatkan seberapa besa pengaruh yang terjadi antar variabel dalam model. Kemudian dilanjutkan dengan perkiraan koefisien jalur yang diperoleh melalui prosedur bootsrapping. Jika t statitik $>$ 1,96 dianggap signifikan pada skor p-values < 0.05, sedangkan untuk melihat arah pengaruhnya digunakan koefisien nilai beta.

\section{Hasil dan Pembahasan}

\section{Hasil Uji Validitas dan Reliabilitas}

Uji instrumen dilakukan terhadap 30 responden. Instrumen dikatakan valid jika $\mathrm{r}_{\text {hitung }}$ $>\mathrm{r}_{\text {tabel }}$ pada $\alpha=0.05$ dengan $\mathrm{r}$ tabel yang digunakan 0,361 . Uji Reliabilitas digunakan untuk pengujian konsistensi hasil pengukuran instrumen yang digunakan. Untuk menguji reliabilitas kuesioner menggunakan Alpha Cronbach's. Jika nilai cronbach's alpha >0.6, maka instrument tersebut dikatakan reliabel.

Hasil pengujian isntrumen penelitian menunjukkan bahwa semua nilai $r$ product moment yang merupakan ukuran validitas $>0.361$, sehingga semua item pada masingmasing variabel penelitian dinyatakan telah valid. Demikian juga dengan nilai Alpha Cronbach's mempunyai nilai $>0.6$, sehingga seluruh variabel juga dinyatakan reliabel.

\section{Analisis SEM-PLS}

\section{Hasil Outer Model}

Setiap dimensi dalam model wajib memenuhi validitas konvergensi, yaitu absolute load factor-nya $>0,7$. Jika tidak memenuhi, maka dimensi tersebut dikeluarkan dari model. Berikut adalah hasil validitas konvergensi: 
Jurnal Nusantara Aplikasi Manajemen Bisnis

Vol. 6 No.2 Tahun 2021

Jurnal Nusantara

Aplikasi Manajemen Bisnis

E-ISSN : 2528-0929 P-ISSN : 2549-5291

Tabel 1. Hasil Convergent Validity

\begin{tabular}{ccccc}
\hline & $\begin{array}{c}\text { Entreprenereul } \\
\text { Marketing }\end{array}$ & Inovasi & $\begin{array}{c}\text { Keunggulan } \\
\text { Kompetitif }\end{array}$ & $\begin{array}{c}\text { Kompetensi } \\
\text { SDM }\end{array}$ \\
\hline X1.1 & & & & 0.829 \\
X1.2 & & & & 0.877 \\
X1.3 & & & 0.847 \\
X1.4 & & & 0.804 \\
X1.5 & & 0.868 & & 0.875 \\
X2.1 & & 0.870 & \\
X2.2 & & 0.864 & & \\
X2.3 & & 0.742 & & \\
X2.4 & & & & \\
Y1.1 & 0.812 & & & \\
Y1.2 & 0.746 & & & \\
Y1.3 & 0.757 & & & \\
Y1.4 & 0.725 & & & \\
Y1.5 & 0.773 & & 0.871 & \\
Y1.7 & 0.816 & & 0.858 & \\
Y2.1 & & & 0.750 & \\
Y2.2 & & & & \\
Y2.3 & & & & \\
\hline
\end{tabular}

Sumber: Output PLS

Tabel 1 menunjukkan bahwa semua dimensi mempunyai outer loading $>0,700$, maka tidak terdapat dimensi yang perlu dihilangkan dari model. Hasil convergent validity juga dapat dilihat secara visual sebagaimana gambar berikut: 


\section{Jurnal Nusantara Aplikasi Manajemen Bisnis}

Vol. 6 No.2 Tahun 2021

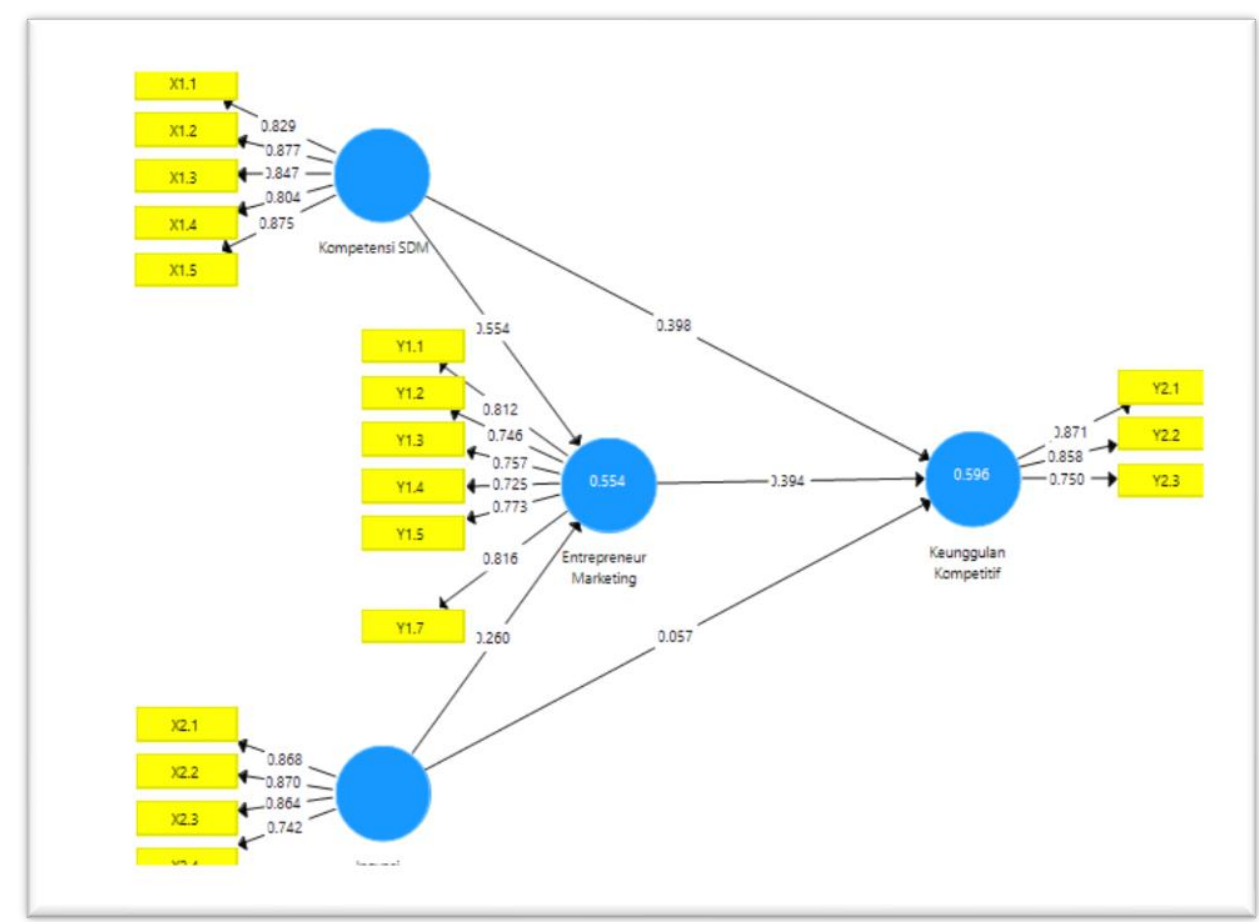

Gambar 2. Hasil convergent validity model SEM-PLS entrpreneurial marketing dan keunggulan kompetitif

Pengukuran model dapat pula menggunakan AVE (average variance extracted) dan $\mathrm{CR}$ (composite reliability), dan berikut hasilnya.

Tabel 2. Hasil Average Variance Extracted (AVE)

\begin{tabular}{lcc}
\hline & $\begin{array}{c}\text { Composite } \\
\text { Reliability }\end{array}$ & $\begin{array}{c}\text { Average Variance } \\
\text { Extracted (AVE) }\end{array}$ \\
\hline Entrepreneur Marketing & 0.898 & 0.596 \\
Inovasi & 0.904 & 0.702 \\
Keunggulan Kompetitif & 0.867 & 0.686 \\
Kompetensi SDM & 0.927 & 0.717 \\
\hline
\end{tabular}

Sumber: Output PLS

Nilai $A V E$ yang direkomendasikan adalah $>0.5$, sedangkan nilai composite reliability $>0.7$. Nilai $A V E$ yang diperoleh berada di atas 0.5 , hal ini memberi arti bahawa variansi yang dapat dijelaskan dimensi adalah di atas $50 \%$. Sedangkan nilai composite reliability > 0,7 berarti seluruh variabel laten mempunyai reliabilitas baik. 


\section{Jurnal Nusantara Aplikasi Manajemen Bisnis}

\section{Jurnal Nusantara}

Aplikasi Manajemen Bisnis

Vol. 6 No.2 Tahun 2021

E-ISSN : 2528-0929 P-ISSN : 2549-5291

\section{Hasil Inner Model}

Berikut ini adalah hasil analisis nilai koefisien determinasi $\left(\mathrm{R}^{2}\right)$ dari inner model.

Tabel 3. Nilai koefisien determinasi $\left(\mathrm{R}^{2}\right)$ pada inner model

\begin{tabular}{lcc}
\hline & R Square & R Square Adjusted \\
\hline Entrepreneurial Marketing & 0.554 & 0.546 \\
Keunggulan Kompetitif & 0.596 & 0.584 \\
\hline
\end{tabular}

Sumber: Output PLS

Makna yang dapat dijelaskan dalam tabel 3 adalah:

a. Variabel laten entrepreneurial marketing memiliki nilai koefisien determinasi 0,546. Hal ini memberikan arti bahwa variasi dari entrepreneurial marketing mampu dijelaskan oleh kompetensi SDM dan inovasi sebesar 54,6\%, adapun sisanya 46,4\% dijelaskan oleh faktor lainnya di luar model.

b. Variabel laten keunggulan kompetitif memiliki nilai koefisien determinasi 0,584. Hal ini memberikan arti bahwa variasi dari keunggulan kompetitif mampu dijelaskan oleh orientasi kompetensi SDM, inovasi, dan entrepreneurial marketing sebesar 58,4\%, adapun selisihnya $41,6 \%$ dijelaskan oleh faktor lain yang berada di luar model.

Estimasi koefisien jalur dari model partial least square tentang entrepreneurial marketing dan keunggulan komptetitf adalah:

Tabel 4. Hasil estimasi model partial least square entrepreneur marketing dan keunggulan kompetitif

\begin{tabular}{|c|c|c|c|c|}
\hline & $\begin{array}{c}\text { Original } \\
\text { Sample }(0)\end{array}$ & $\begin{array}{c}\text { Standard Deviation } \\
\text { (STDEV) }\end{array}$ & $\begin{array}{l}\text { T Statistics } \\
(\mid \text { O/STDEV } \mid)\end{array}$ & $\begin{array}{c}\mathbf{P} \\
\text { Values }\end{array}$ \\
\hline $\begin{array}{l}\text { Entrepreneurial Marketing -> } \\
\text { Keunggulan Kompetitif }\end{array}$ & 0.394 & 0.119 & 3.304 & 0.001 \\
\hline $\begin{array}{l}\text { Inovasi -> Entrepreneurial } \\
\text { Marketing }\end{array}$ & 0.260 & 0.098 & 2.640 & 0.009 \\
\hline $\begin{array}{l}\text { Inovasi -> Keunggulan } \\
\text { Kompetitif }\end{array}$ & 0.057 & 0.100 & 0.564 & 0.573 \\
\hline $\begin{array}{l}\text { Kompetensi SDM -> } \\
\text { Entrepreneurial Marketing }\end{array}$ & 0.554 & 0.104 & 5.339 & 0.000 \\
\hline $\begin{array}{l}\text { Kompetensi SDM -> } \\
\text { Keunggulan Kompetitif }\end{array}$ & 0.398 & 0.128 & 3.111 & 0.002 \\
\hline
\end{tabular}

Sumber: Output PLS

Hasil hubungan sebab akibat antar variabel laten dinyatakan dalam gambar berikut: 


\section{Jurnal Nusantara Aplikasi Manajemen Bisnis}

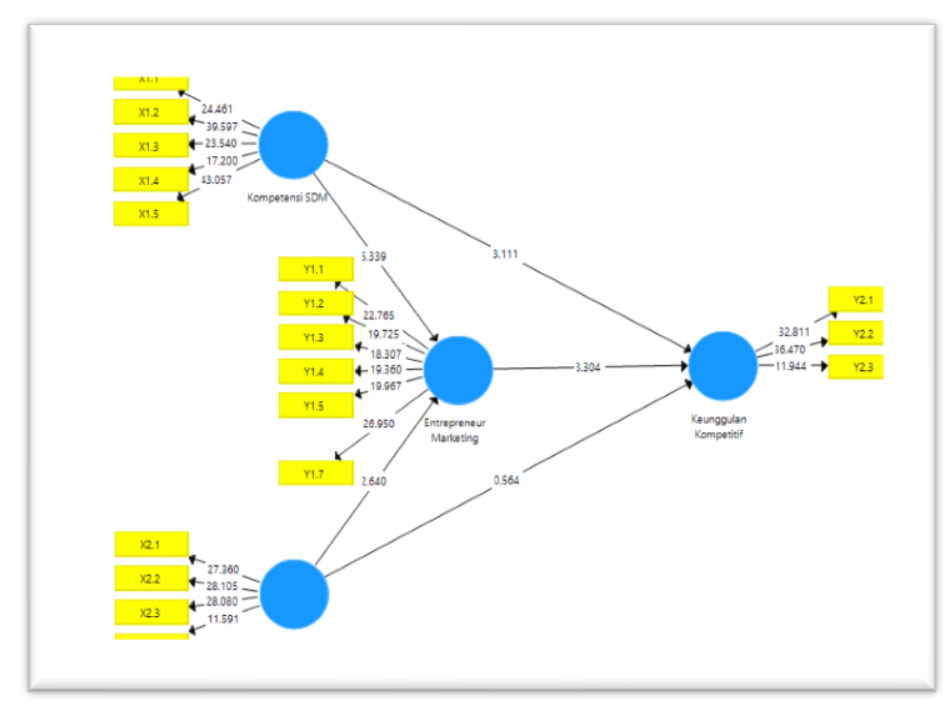

Gambar 3. Hasil pemodelan SEM-PLS entrepreneurial marketing dan keunggulan kompetitif

Hasil estimasi model penelitian adalah sebagai sebagai berikut:

$$
\begin{aligned}
& E M=0.554 K S+0.260 I S \\
& K K=0.398 K S+0.057 I S+0.394 E M
\end{aligned}
$$

Persamaan struktural tersebut dapat dijelaskan sebagai-berikut:

1. Variabel laten kompetensi SDM berpengaruh positif signifikan terhadap entrepreneurial marketing (EM) dengan hasil estimasi koefisien jalur sebesar 0.554 dan p-value 0.000 . Hal ini memberi arti bahwa semakin bagus kompetensi SDM (KS) maka entrepreneur marketing (EM) akan semakin baik.

2. Variabel laten inovasi berpengaruh positif signifikan terhadap entrepreneurial marketing (EM) dengan hasil perkiraan koefisien jalur sebesar 0.260 dan p-value 0.009 . Hal ini memberi arti bahwa semakin baik inovasi (IS) maka entrepreneurial marketing (EM) juga akan semakin baik.

3. Variabel laten kompetensi SDM berpengaruh positif signifikan terhadap keunggulan kompetitif dengan hasil perkiraan koefisien jalur sebesar 0.398 dan $p$-value 0.002 . Hal ini memberi arti bahwa semakin bagus kompetensi SDM maka keunggulan kompetitif (KK) akan semakin naik.

4. Variabel laten inovasi (berpengaruh positif, tetapi tidak signifikan terhadap keunggulan kompetitif dengan hasil perkiraan koefisien jalur sebesar 0.057 dan p-value 0.573. Artinya semakin inovatif, maka keunggulan kompetitif akan semakin naik, namun peningkatan yang terjadi secara statistik tidak signifikan.

5. Variabel laten entrepreneurial marketing berpengaruh positif signifikan terhadap keunggulan kompetitif dengan hasil perkiraan koefisien jalur sebesar 0.394 dan $p$-value 0.001. Hal ini memberi makna bahwa semakin baik entrepreneurial marketing (EM) maka keunggulan kompetitif juga semakin naik. 


\section{Jurnal Nusantara Aplikasi Manajemen Bisnis}

Tabel 5 di bawah ini digunakan untuk melihat pengaruh tidak langsung kompetensi SDM dan inovasi terhadap keunggulan kompetitif melalui entrepreneurial marketing (EM).

Tabel 5. Pengaruh tidak langsung (indirect effect)

\begin{tabular}{lcccc}
\hline & $\begin{array}{c}\text { Original } \\
\text { Sample } \\
(\mathbf{O})\end{array}$ & $\begin{array}{c}\text { Standard } \\
\text { Deviation } \\
(\text { STDEV })\end{array}$ & $\begin{array}{c}\text { T Statistics } \\
(\mid \mathbf{O} / \text { STDEV })\end{array}$ & $\begin{array}{c}\text { P } \\
\text { Values }\end{array}$ \\
\hline $\begin{array}{l}\text { Entrepreneurial Marketing -> Keunggulan } \\
\text { Kompetitif }\end{array}$ & & & & \\
$\begin{array}{l}\text { Inovasi -> Entrepreneurial Marketing } \\
\text { Inovasi -> Keunggulan Kompetitif } \\
\text { Kompetensi SDM -> Entrepreneurial }\end{array}$ & 0.102 & 0.044 & 2.342 & $\mathbf{0 . 0 2 0}$ \\
$\begin{array}{l}\text { Marketing } \\
\text { Kompetensi SDM -> Keunggulan Kompetitif }\end{array}$ & 0.218 & & & \\
\hline Sumber: Output PLS & & & & \\
\end{tabular}

Menurut tabel 5 dapat dijelaskan pengaruh tidak langsung komptensi SDM dan inovasi terhadap keunggulan kompetitif melalui entrepreneurial marketing.

1. Koefisien jalur pengaruh tidak langsung kompetensi SDM terhadap keunggulan kompetitif melalui entrepreneurial marketing adalah sebesar 0.218 dengan $p$-value 0.017 (signifikan pada level 5\%). Koefisien jalur tidak langsung yang positif menunjukkan bahwa semakin tinggi kompetensi SDM, maka keunggulan kompetitif juga akan semakin naik dengan dimediasi entrepreneurial marketing.

2. Koefisien jalur pengaruh tidak langsung inovasi (IS) terhadap keunggulan kompetitif (KK) melalui entrepreneurial marketing adalah sebesar 0.102 dengan p-value 0.020 (signifikan pada level 5\%). Koefisien jalur tidak langsung yang positif menunjukkan bahwa semakin baik inovasi, maka keunggulan kompetitif juga akan semakin naik dengan dimediasi entrepreneurial marketing.

\section{Pembahasan}

\section{Pengaruh Kompetensi SDM terhadap Entrepreneurial Marketing}

Hasil hitung statistik yang dilakukan memperlihatkan bahwa kompetensi SDM berpengaruh positif dan signifikan terhadap entrepreneurial marketing. Hal ini memberi makna bahwa semakin kompeten SDM yang dimiliki, maka semakin bagus entrepreneurial marketing-nya. Kompetensi SDM dalam penelitian ini terdiri dari empat indikator, yaitu pengetahuan, keterampilan, kepercayaan dan motivasi. Meskipun pengetahuan dan keterampilan yang dimiliki oleh pelaku industri makanan dan minuman di Jawa Timur masih terbatas, tetapi dengan kepercayaan dan motivasi yang tinggi berdampak positif terhadap entrepreneurial marketing. Entrepreneurial marketing sangat diperlukan oleh pelaku UMKM, karena di dalamnya terdapat strategi unik yang tidak dimiliki oleh usaha besar. Oleh sebab itu, guna meningkatkan entrepreneurial marketing, para pelaku industri makanan minuman di Jawa Timur perlu meningkatkan semua demensi kompetensi SDM. Hasil penelitian ini sesuai dengan pendapat [50] dan [51] yang menyatakan bahwa SDM 


\section{Jurnal Nusantara Aplikasi Manajemen Bisnis}

merupakan aset yang sangat menentukan lancarnya kegiatan organisasi. Oleh sebab itu mengembangkan kompetensi yang relevan dalam pengelolaan usaha merupakan langkah penting menuju UMKM yang unggul dan kompetitif yang berkelanjutan. Hasil ini sekaligus mendukung temuan [38] dan [39] yang menyatakan bahwa kompetensi SDM berpengaruh signifikan terhadap entrepreneurial marketing.

\section{Pengaruh Inovasi terhadap Entrepreneurial Marketing}

Hasil hitung statistik yang dilakukan memperlihatkan bahwa inovasi berpengaruh positif dan signifikan terhadap entrepreneurial marketing. Inovasi dalam penelitian ini terdiri dari empat indikator, yaitu inovasi dalam produk, proses, pemasaran dan organisasi. Temuan ini memberi makna jika pelaku industi makanan minuman semakin inovatif, makan akan semakin meningkatkan entrepreneurial marketing. Inovasi merupakan keharusan bagi pelaku usaha untuk dapat bertahan dan mengembangkan usahanya, mengingat persaingan usaha yang semakin kompetitif, disamping perilaku masyarakat yang selalu dinamis menyesuaiakan situasi, kondisi dan perkembangan teknologi. Sebagai contoh adalah pada masa pandemi covid 19 saat ini.

Kondisi pandemi mengharuskan pelaku industri makanan-minuman beradaptasi dengan perilaku konsumen yang berubah akibat adanya keijakan pembatasan dari pemerintah. Pelaku usaha harus mampu memunculkan inovasi baru, ide-ide kreatif, ide baru yang menawarkan produk dan layanan yang inovatif sesuai kebutuhan pasar. Oleh sebab itu, inovasi menjadi semakin penting, tidak hanya sebagai alat mempertahankan kontinuitas perusahaan, tetapi juga sebagai senjata utama dalam persaingan. Perusahaan yang mampu mengembangkan produk, layanan, dan proses baru akan mampu menciptakan citra yang lebih baik di mata konsumen . Proses ini yang pada akhirnya memberikan ciri khusus yang membedakannya dengan para pesaing. Hasil penenlitian ini mendukung temuan [17]; [38]; [18]; [11] yang menyatakan bahwa inovasi berpengaruh signifikan terhadap entrepreneurial marketing.

\section{Pengaruh Kompetensi SDM terhadap Keunggulan Kompetitif}

Hasil hitung statistik menunjukkan bahwa kompetensi SDM berpengaruh positif signifikan terhadap keunggulan kompetitif. Temuan ini memberi makna bahwa semakin kompeten SDM yang dimiliki oleh pelaku industri makanan-minuman di Jawa Timur, maka akan meningkatkan keunggulan kompetitif. Kompetensi SDM terdiri dari 5 indikator, yaitu pengetahuan, keterampilan, motivasi, kepercayaan dan konsep diri. SDM yang memiliki pengetahuann yang luas, berdampak pada kemampuan analisis yang tajam, memiliki keterampilan akan berdampak pada efisiensi dan efektivitas dalam menyelesaikan pekerjaan, motivasi yang tinggi berdampak pada produktivitas, kepercayaan diri mengakibatkan mudah beradaptasi dan keberanian mengambil risiko, sedangkan konsep diri yang positif akan menjadikan selalu optimis dan berfikir positif. Oleh sebab itu, SDM sebagai aset penting harus direncanakan dan dikelola dengan baik, sejak rekrutmen, penempatan, peningkatan pengetahuan, keterampilan dan selalu menjaga hubungan baik sehingga kompetensi yang dimiliki dapat meningkatkan keunggulan kompetitif perusahaan. Perusahaan juga harus memiliki standar kompetensi sumber daya manusia tertentu untuk mengisi posisi di perusahaan agar memiliki keunggulan kompetitif. Temuan 


\section{Jurnal Nusantara Aplikasi Manajemen Bisnis}

\section{Jurnal Nusantara}

Vol. 6 No.2 Tahun 2021

Aplikasi Manajemen Bisnis

E-ISSN : 2528-0929 P-ISSN : 2549-5291

ini mendukung temuan [16] dan [14] yang menyatakan bahwa kompetensi SDM berpengaruh terhadap keunggulan kompetitif.

\section{Pengaruh Inovasi terhadap Keunggulan Kompetitif}

Hasil hitung statistik memperlihatkan bahwa inovasi memiliki pengaruh positif tetapi tidak seginifikan terhadap keunggulan kompetitif. Keterbatasan sumberdaya yang dimiliki oleh pelaku industri makanan-minuman di Jawa Timur mengakibatkan cenderung kesulitan dalam melakukan inovasi. Inovasi memerlukan pengorbanan lebih, sedangkan sumberdaya yang dimiliki oleh usaha mikro kecil terbatas [25]. Kurangnya permodalan yang dimiliki oleh pelaku usaha mikro kecil dengan lebih mengandalkan pada modal sendiri yang jumlahnya terbatas menyebabkan usaha mikro kecil kesulitan melakukan inovasi dalam memproduksi produknya. Fakta di lapangan menyatakan paling banyak usaha kecil yang berkembang secara tradisional ialah usaha yang dibangun oleh sebuah keluarga secara turun-temurun. Keterbatasan UKM, seperti minimnya tingkat pendidikan, pengetahuan, juga rendahnya keterampilan sangat mempengaruhi terhadap manajemen dalam pengelolaan usaha, sehingga usaha yang dibangun sulit untuk berkembang secara optimal. Selain itu pengaruh perdagangan bebas AFTA yang telah berlangsung sejak tahun 2003, dan APEC pada tahun 2020 diketahui memiliki pengaruh yang signifikan terhadap kemampuan usaha kecil dan menengah untuk bisa bersaing pada ranah perdagangan bebas, sehingga pelau usaha mikro kecil didorong agar dapat produktif dan efesien untuk meciptakan produk yang relevan dengan sistem pemasaran global maupun dengan kualitas produk yang tinggi. Pernyataan ini berseberangan dengan temuan [17]; [36]; [18]; [11] yang menyatakan bahwa inovasi secara langsing berpengaruh signifikan terhadap terhadap keuanggulan kompetitif.

\section{Pengaruh Entrepreneurial Marketing terhadap Keunggulan Kompetitif}

Hasil statistik memperlihatkan bahwa entrepreneurial marketing berpengaruh secara positif signifikan terhadap keunggulan kompetitif. Hasil ini memiliki makna bahwa semakin bagus entrepreneurial marketing, maka akan dapat meningkatkan keunggulan kompetitif industri makanan-minuman di Jawa Timur. Entrepreneurial marketing pelaku industri makanan-minuman di Jawa Timur ditunjukkan dengan kemampuannya untuk selalu proaktif, adaptif terhadap perubahan, berani mengambil risiko, fokus pada peluang dan intensitas pada pelanggan. Memang pada dasarnya pemasaran produk usaha mikro kecil lebih tepat adalah enterpreneurial marketing, karena sebagian besar usaha mikro kecil memiliki sumber daya yang terbatas, sehingga harus menggunakan cara yang kreatif [25]. Menurut [35] salah satu taktik yang dapat digunakan dalam menciptakan keunggulan kompetitif di Era 21 yaitu menggunakan startegi entrepreneurial marketing.

Berkaitan dengan hal tersebut, penting bagi pelaku usaha menguasai entrepreneurial marketing guna mendukung kegiatan pemasarannya, sehingga kesempatan untuk mencapai keunggulan kompetitif dapat diwujudkan. Hasil tersebut mendukung penelitian yang sudah dilakukan oleh [8]; [9]; [10] yang menyatakan bahwa entrepreneurial marketing berpengaruh signfikan terhadap keunggulan kompetitif.

\section{Kesimpulan}




\section{Jurnal Nusantara Aplikasi Manajemen Bisnis}

\section{Jurnal Nusantara}

Aplikasi Manajemen Bisnis

Vol. 6 No.2 Tahun 2021

Kesimpulan dalam penelitian ini adalah kompetensi SDM dan entrepreneurial marketing secara parsial berpengaruh positif signifikan terhadap keunggulan kompetitif, kompetensi SDM dan inovasi secara signifikan berpengaruh terhadap entrepreneurial marketing, sedangkan inovasi tidak berpengaruh signifikan terhadap keunggulan kompetitif pada industri makanan dan minuman di Jawa Timur. Namun demikian, melalui mediasi entrepreneurial marketing, baik kompetensi SDM maupun inovasi berpengaruh signifikan terhadap keunggulan bersang. Kompetensi SDM merupakan variabel yang lebih dominan mempengaruhi keuanggulan kompetitif dibandingkan inovasi. Hal ini menunjukkan betapa penting SDM dalam menciptakan keunggulan kompetitif. Inovasi hanya akan terjadi jika perusahaan memiliki SDM yang kompeten dan ditunjang kemampuan dari sisi finansiil, karena inovasi memutuhkan modal. Mengingat pada umumnya pelaku industri makanan-minuman masih terbatas dalam hal kompetensi SDM dan inovasi, maka untuk mencapai keunggulan kompetitif perlu memaksimalkan jiwa entrepreneur yang pada umumnya melekat pada karakter pelaku UMKM dengan mengimplikasikannya pada entrepreneurial marketing.

\section{Daftar Rujukan}

[1] Eggers, F., O’Dwyer, M., Kraus, S., Vallaster, C., \& Güldenberg, S. (2013). The impact of Brand Authenticity on Brand Trust and SME growth: A CEO perspective. Journal of World Business, 48(3). https://doi.org/10.1016/j.jwb.2012.07.018.

[2] Muhammad, M. Z.-, Char, A. K., Yasoa', M. R. bin, \& Hassan, Z. (2009). Small and Medium Enterprises (SMEs) Competing in the Global Business Environment: A Case of Malaysia. International Business Research, 3(1). https://doi.org/10.5539/ibr.v3n1p66.

[3] Naidoo, V. (2010). Firm survival through a crisis: The influence of market orientation, marketing innovation and business strategy. Industrial Marketing Management, 39(8). https://doi.org/10.1016/j.indmarman.2010.02.005.

[4] Eniola, A., \& Ektebang, H. (2014). SME firms Performance In Nigeria: Competitive Advantage and its Impact. International Journal of Research Studies in Management, 3(2). https://doi.org/10.5861/ijrsm.2014.854.

[5] Wahyudin, N. (2015). Analisis Faktor-Faktor yang Mempengaruhi Keunggulan Bersaing untuk Meningkatkan Kinerja Perguruan Tinggi Swasta (PTS) pada Sekolah Tinggi dan Akademi di Semarang. Holistic Journall of Management Research.

[6] Satria Widiarsa, I. B. I., \& Sulistyawati, E. (2018). Peran Keunggulan Kompetitif Memediasi Pengaruh Green Marketing terhadap Keputusan Pembelian (Studi Pada Perusahaan Earth Café di Seminyak). E-Jurnal Manajemen Universitas Udayana, 7(7). https://doi.org/10.24843/ejmunud.2018.v07.i07.p01.

[7] Hardum Suprianus Edi. (2021). Sektor Makanan Minuman Penyumbang PDB terbesar Non Migas. https://www.beritasatu.com/ekonomi/752649/sektor-makanan-danminuman-penyumbang-pdb-industri-nonmigas-terbesar, diakses tanggal 10 April 2021.

[8] Becherer, R. C., Helms, M. M., \& McDonald, J. P. (2012). The Effect of Entrepreneurial Marketing on Outcome Goals in SMEs. New England Journal of Entrepreneurship. https://doi.org/10.1108/neje-15-01-2012-b001.

[9] Hidayatullah, S., Firdiansjah, A., Patalo, R. G., \& Waris, A. (2019). The effect of Entrepreneurial Marketing and Competitive Advantage on Marketing Performance. 


\section{Jurnal Nusantara Aplikasi Manajemen Bisnis}

\section{Jurnal Nusantara}

Vol. 6 No.2 Tahun 2021

Aplikasi Manajemen Bisnis

E-ISSN : 2528-0929 P-ISSN : 2549-5291

International Journal of Scientific and Technology Research.

[10] Mahrous, A., Genedy, M. A., \& Kalliny, M. (2020). The Impact of Characteristics of Intra-Organizational Environment on Entrepreneurial Marketing Intensity and Performance in Egypt. Journal of Entrepreneurship in Emerging Economies. https://doi.org/10.1108/JEEE-08-2019-0115.

[11] Morrish, S. C., Miles, M. P., \& Deacon, J. H. (2010). Entrepreneurial Marketing: Acknowledging the Entrepreneur and Customer-Centric Interrelationship. Journal of Strategic Marketing, 18(4). https://doi.org/10.1080/09652541003768087.

[12] Green, K. W., Zelbst, P. J., Meacham, J., \& Bhadauria, V. S. (2012). Supply Chain Management: An International Journal Green Supply Chain Management Practices: impact on Performance. Supply Chain Management: An International Journal, 17.

[13] Jones, C. (2010). Materializing piety: Gendered Anxieties About Faithful Consumption in Contemporary Urban Indonesia. American Ethnologist, 37(4). https://doi.org/10.1111/j.1548-1425.2010.01275.x.

[14] Alajmi, S. A., \& Alenezi, M. A. (2016). Human Resource Management Practices And Competitive Advantage: The Mediator Role Of Person-Organization Fit. Global Journal of Human Resource Management.

[15] Mitchelmore, S., \& Rowley, J. (2010). Entrepreneurial Competencies: A Literature Review and Development Agenda. In International Journal of Entrepreneurial Behaviour \& Research. https://doi.org/10.1108/13552551011026995.

[16] Nemli Çalişkan, E. (2010). The Impact Of Strategic Human Resource Management On Organizational Performance Stratejik İnsan Kaynaklari Yönetiminin Firma Performansina Etkisi Özet. Journal of Naval Science and Engineering, 6(2).

[17] Afriyie, S., Du, J., \& Musah, A. A. I. (2019). Innovation and Marketing Performance of SME in an Emerging Economy: The Moderating Effect of Transformational Leadership. Journal of Global Entrepreneurship Research, 9(1), 1-25.

[18] Miles, M. P., \& Darroch, J. (2006). Large firms, Entrepreneurial Marketing Processes, and the Cycle of Competitive Advantage. European Journal of Marketing, 40(5-6). https://doi.org/10.1108/03090560610657804.

[19] Chang, C. H. (2011). The Influence of Corporate Environmental Ethics on Competitive Advantage: The Mediation Role of Green Innovation. Journal of Business Ethics.

[20] Dereli, D. D. (2015). Innovation Management in Global Competition and Competitive Advantage. Procedia - Social and Behavioral Sciences. https://doi.org/10.1016/j.sbspro.2015.06.323.

[21] Le, P. B., \& Lei, H. (2018). The Effects of Innovation Speed and Quality on Differentiation and Low-Cost Competitive Advantage: The Case of Chinese Firms. Chinese Management Studies. https://doi.org/10.1108/CMS-10-2016-0195.

[22] Mathenge, J. (2013). The Effect of Innovation on Competitive Advantage of Telecommunication Companies in Kenya. In a Research Project Submitted in Partial Fulfillment of the Requirements for the Degree of Master of Business Administration of the University of Nairobi.

[23] Varadarajan, R. (2011). Conjectures on Innovation Drivers in an Emerging Market: India. In Handbook of Research in International Marketing, Second Edition. https://doi.org/10.4337/9781849806121.00013.

[24] Udriyah, Tham, J., \& Ferdous Azam, S. M. (2019). The Effects of Market Orientation 


\section{Jurnal Nusantara Aplikasi Manajemen Bisnis}

\section{Jurnal Nusantara}

Aplikasi Manajemen Bisnis

Vol. 6 No.2 Tahun 2021

and Innovation on Competitive Advantage and Business Performance of Textile SMEs. Management Science Letters. https://doi.org/10.5267/j.msl.2019.5.009.

[25] Sadiku-Dushi, N., Dana, L. P., \& Ramadani, V. (2019). Entrepreneurial Marketing Dimensions and SMEs Performance. Journal of Business Research. https://doi.org/10.1016/j.jbusres.2019.03.025.

[26] Kumar, V., \& Pansari, A. (2016). Competitive Advantage through Engagement. In Journal of Marketing Research. https://doi.org/10.1509/jmr.15.0044.

[27] Hinterhuber, A. (2013). Can Competitive Advantage be Predicted? Management Decision. https://doi.org/10.1108/00251741311326572.

[28] Porter, Michael E. (1998). Competitive Advantage: Creating and Sustaining Superior Performance. In The Free. https://doi.org/10.1016/j.neubiorev.2009.11.015.

[29] Zekiri, J., \& Nedelea, A. (2012). Strategies for Achieving Competitive Advantage. The USV Annals of Economics and Public Administration, 11(2), 63-73.

[30] Li, S., Ragu-Nathan, B., Ragu-Nathan, T. S., \& Rao, S. S. (2006). The Impact of Supplychain Management Practices on Competitive Advantage and Organizational Performance. Omega:The International Journal of Management Science, 34, 107 - 124.

[31] Morris, M. H., Schindehutte, M., \& LaForge, R. W. (2002). Entrepreneurial Marketing: A Construct for Integrating Emerging Entrepreneurship and Marketing Perspectives. Journal of Marketing Theory and Practice, 10(4). https://doi.org/10.1080/10696679.2002.11501922.

[32] Jones, R., \& Rowley, J. (2011). Entrepreneurial Marketing in Small Businesses: A Conceptual Exploration. International Small Business Journal. https://doi.org/10.1177/0266242610369743.

[33] Carson, D., Cromie, S., McGotwan, P., \& Hill, J. (1995). Marketing and Entrepreneurship in SMEs : An Innovative Appro. European Journal of Marketing.

[34] Moore, R. C. (2017). Childhood's Domain: Play and Place in Child Development. In Childhood's Domain: Play and Place in Child Development. https://doi.org/10.4324/9781315121895.

[35] Morrish, S. C. (2011). Entrepreneurial Marketing: A Strategy for the Twenty-first Century? Journal of Research in Marketing and Entrepreneurship, 13(2). https://doi.org/10.1108/14715201111176390.

[36] Autio, E., Kenney, M., Mustar, P., Siegel, D., \& Wright, M. (2014). Entrepreneurial Innovation: The Importance of context. Research Policy, 43 (7). https://doi.org/10.1016/j.respol.2014.01.015.

[37] Agyapong, F. O., Agyapong, A., \& Poku, K. (2017). Nexus between Social Capital and Performance of Micro and Small Firms in an Emerging Economy: The Mediating Role of Innovation. Cogent Business and Management, 4(1). https://doi.org/10.1080/23311975.2017.1309784.

[38] Shahhosseini, V., \& Sebt, M. H. (2011). Competency-Based Selection and Assignment of Human Resources to Construction Projects. Scientia Iranica. https://doi.org/10.1016/j.scient.2011.03.026.

[39] Franco, M., Santos, M. de F., Ramalho, I., \& Nunes, C. (2014). An Exploratory Study of Entrepreneurial Marketing in SMEs: The Role Of The Founder-Entrepreneur. Journal of Small Business and Enterprise Development. https://doi.org/10.1108/JSBED-10-20120112 . 


\section{Jurnal Nusantara Aplikasi Manajemen Bisnis}

\section{Jurnal Nusantara}

Aplikasi Manajemen Bisnis

Vol. 6 No.2 Tahun 2021

E-ISSN : 2528-0929 P-ISSN : 2549-5291

[40] Gordon. (1998). Pembelajaran Kompetensi. Jakarta. Rineka Cipta.

[41] Ceylan, C. (2013). Commitment-based HR Practices, Different Types of Innovation Activities and Firm Innovation Performance. International Journal of Human Resource Management. https://doi.org/10.1080/09585192.2012.680601

[42] Andries, P., \& Czarnitzki, D. (2014). Small Firm Innovation Performance and Employee Involvement. Small Business Economics. https://doi.org/10.1007/s11187-014-9577-1.

[43] Prajogo, D. I. (2016). The Strategic Fit between Innovation Strategies and Business Environment in Delivering Business Performance. International Journal of Production Economics. https://doi.org/10.1016/j.ijpe.2015.07.037.

[44] Atalay, M., Anafarta, N., \& Sarvan, F. (2013). The Relationship Between Innovation and Firm Performance: An Empirical Evidence from Turkish Automotive Supplier Industry. Procedia - Social and Behavioral Sciences. https://doi.org/10.1016/j.sbspro.2013.04.026 https://doi.org/10.1007/s10551-011-0914-x.

[45] Vaccaro, I. G., Jansen, J. J. P., van den Bosch, F. A. J., \& Volberda, H. W. (2012). Management Innovation And Leadership: The Moderating Role of Organizational Size. Journal of Management Studies. https://doi.org/10.1111/j.1467-6486.2010.00976.x

[46] Collinson, E., \& Shaw, E. (2001). Entrepreneurial Marketing - a Historical Perspective on Development and Practice. Management Decision, 39(9). https://doi.org/10.1108/EUM0000000006221.

[47] OECD/Eurostat. (2005). Oslo Manual: Guidelines for Collecting and Interpreting Innovation Data, 3rd Edition, The Measurement of Scientific and Technological Activities. In Communities: Vol. Third edit.

[48] Cooper, D. R., \& Schindler, P. S. (2003). Business Research Methods. In Business.

[49] Ghozali \& Latan. (2015). Partial Least Square SEM (PLS - SEM). Partial Least Square.

[50] Ahmad, N. H., Halim, H. A., \& Zainal, S. R. M. (2010). Is Entrepreneurial Competency the Silver Bullet For SME Success in a Developing Nation? International Business Management. https://doi.org/10.3923/ibm.2010.67.75

[51] Gerardo Barroso Tanoira, F., \& Alberto Santos Valencia, R. (2014). Knowledge Management, Entrepreneurial Competencies and Organizational Development in Micro and Small Enterprises in Rural Regions in the State of Yucatan, Mexico. European Scientific Journal, 10(1). 